\title{
Effects of mixed essential oils from eucalyptus, thyme and anise on composition, coagulation properties and antioxidant capacity of the milk of dairy cows
}

\author{
K. Giller ${ }^{1,3}$, T. Rilko ${ }^{1}$, E. Manzocchi' ${ }^{1}$ S. Hug ${ }^{2}$, R. Bolt ${ }^{2}$ and M. Kreuzer ${ }^{1}$ \\ ${ }^{1}$ ETH Zurich, Institute of Agricultural Sciences, Universitaetstrasse 2, 8092 Zurich, Switzerland \\ ${ }^{2}$ Strickhof, Competence Centre for Education and Services in the Agri-Food Sector, Eschikon 21, 8315 Lindau, Switzerland
}

KEY WORDS: milk fat, milk protein, milk yield, phenols, plant extracts, cheese-making properties

Received: 2 September 2019

Revised: 9 January 2020

Accepted: 2 March 2020
${ }^{3}$ Corresponding author:

e-mail: katrin.giller@usys.ethz.ch
ABSTRACT. Essential oils (EO) are natural plant secondary compounds prevalent in various plants. They are characterized by an intense aroma and bioactive properties, which may influence intake, digestion, metabolism, performance and milk composition of livestock. In the present study, a commercial powdery product containing EO from eucalyptus, thyme and anise was fed at $25 \mathrm{~g} /$ day (= $5 \mathrm{~g}$ EO; following the producer's recommendation) to 24 cows yielding $36 \mathrm{~kg} /$ day of energy-corrected milk (ECM). Feed intake and milk yield were recorded. The milk composition was analysed using an infrared spectrophotometer, and the coagulation properties were determined on a Lattodinamografo. Milk total phenol content and antioxidant capacity were photometrically analysed. The EO feeding resulted in a dry matter intake (DMI) which was higher by $4 \%$ compared to the control group, whereas ECM (32.8 vs $32.0 \mathrm{~kg} /$ day) was slightly but not significantly higher. Feed efficiency (1.67 vs $1.64 \mathrm{~kg} \mathrm{DMl} / \mathrm{kg}$ ECM) was not affected. The EO supplementation did not affect milk composition (fat, protein, lactose and urea) and coagulation properties. It significantly increased somatic cell count, but to an uncritical level. The EO did not enhance total phenol content and antioxidant capacity of milk. In conclusion, the investigated EO mix could be used for its main purpose according to the producer's statements, namely to combat respiratory diseases, without impairing milk yield as well as milk compositional and technological properties. Higher supplementation levels than those recommended might have more pronounced effects on the variables investigated. Further studies are required to evaluate if the supplementation with higher doses would be favourable or unfavourable.

\section{Introduction}

Essential oils (EO) are complex mixtures of naturally occurring, low molecular weight, heterogeneous plant secondary metabolites (Tisserand and Young, 2013). In contrast to oils composed of fatty acids, they are usually volatile or semi-volatile. The term 'essential' does not refer to the oil being indispensable for an organism, but rather containing the 'essence', the specific aroma, fragrance and flavour of the respective plant (Tisserand and Young, 2013). The EO are usually extracted from plant materials by distillation or cold pressing, but solvent extraction is also possible. So far, around 3000 different EO have been extracted from a wide range of plants. Plant EO can differ substantially in composition, but typically comprise two chemical classes, namely terpenes (including their oxidized derivatives, namely terpenoids) and shikimates, with the latter being less abundant and occurring mainly in the form of 
phenylpropanoids (Tisserand and Young, 2013). The majority of EO are complex mixtures of monoand sesquiterpenes. Also, a variety of additional low molecular weight components such as phenols, alcohols, aldehydes, lactones, ketones, ethers and esters can be present in the EO (Moghaddam and Mehdizadeh, 2017). Individual EO compounds were found to be effective, but studies comparing the effects of single EO components to complex EO mixtures came to the conclusion that there are synergistic effects between major and minor components, resulting in greater antibacterial activity than the action of isolated major components (Lambert et al., 2001).

Since ancient times, EO have been applied to treat various health problems and they are still used as natural therapeutics today. In this context, the pharmacological effects of dietary EO were also scientifically investigated. The EO are described to possess, among others, anti-inflammatory, antioxidant, antihypertensive, immunomodulatory, expectorant and antimicrobial properties (Moghaddam and Mehdizadeh, 2017). It is suggested that not only humans but also animals, including livestock, can benefit from these properties. In this context, strong antimicrobial activities were observed for EO from rosemary, oregano, lemongrass, thyme and turmeric (summarized by Burt, 2004). Their single constituents, including thymol, eugenol, geraniol and carvacrol, were shown to inhibit the growth of certain bacteria, and this already at very low concentrations of 0.05 to $5 \mu \mathrm{l} / \mathrm{ml}$ medium (summarized by Burt, 2004). It has been suggested that the structurally similar thymol and carvacrol, present in thyme EO, increase the permeability of the bacterial cell wall, hence explain the antimicrobial activity of the thyme EO (Lambert et al., 2001). Synthetic antibiotics increase feed efficiency in ruminants but their use as feed additives has been prohibited in the European Union since 2006. Therefore, EO are being investigated as a potential alternative.

It should be taken into account that EO may impair palatability of the diet, thereby resulting in decreased feed intake (described by Hristov et al. (2013) for oregano EO). On the other hand, when applied as silage additives, EO might rather improve the palatability of the diet by promoting silage stability and thus even increase feed intake (Soycan-Önenç et al., 2015). Studies reporting no (Hristov et al., 2013) or the positive effects (Giannenas et al., 2011) of EO on animal performance are indications of the natural variability in the bioactivity and bioavailability of different EO. This phenomenon might also be decisive for the variability of the effects on milk composition and properties that have already been observed(Benchaaretal.,2007; Spangheroetal.,2009; Santos et al., 2010; Wall et al., 2014). Silva Filho et al. (2017) showed that EO tended to reduce the somatic cell count (SCC) of the milk and thus may help to reduce the risk for mastitis. As a high SCC contributes to impaired cheese-making properties of the milk (Le Maréchal et al., 2011), EO might also be effective in maintaining appropriate technological characteristics of milk, even under challenging conditions.

In order to be able to directly influence milk properties, EO need to be transferred from feed to milk in sufficient amounts. Volatile compounds might enter the metabolism of cows either by ingestion and absorption from the gastrointestinal tract or by inhalation and pulmonary diffusion into the blood. Several studies showed that the terpene content of the milk reflects the terpene content of the ingested feed and, consequently, the feed's botanical composition (Tornambé et al., 2006). This suggests that terpenes and other antioxidant compounds that are transferred to the milk might be able to increase oxidative stability of milk.

The aim of the present study was to investigate the effect of a commercially available mixture of EO from three plants rich in EO, eucalyptus (Eucalyptus globulus), thyme (Thymus vulgaris) and anise (Pimpinella anisum). Three hypotheses were tested: (1) the tested EO mix does not affect feed intake, but improves feed efficiency by increasing or maintaining milk yield; (2) it does not impair milk composition and milk coagulation properties; and (3) a significant amount of phenols is transferred from the EO mix to the milk and, along with that, the antioxidant capacity of the milk is promoted.

\section{Material and methods}

\section{Diets, animals and experimental design}

The experiment was approved by the Cantonal Veterinary Office (license number ZH031/19, Switzerland). Two different diets, both based on a total mixed ration (TMR), were compared in the present experiment with dairy cows, where one was supplemented with an organic EO product (Bronch-Arom ${ }^{\circledR}$ B, Dr. Schaette Produkte; SaluVet GmbH, Bad Waldsee, Germany). According to the producer's information, this product contains $20 \%$ of EO extracted via steam distillation, thereof $75 \%$ from eucalyptus, thyme and anise (in decreasing amounts). In the product, the EO were mixed with wheat bran, brewer's yeast and diatomaceous earth and processed to a powder. As stated by the manufacturer, 
the product is intended to prevent and mitigate respiratory diseases and to increase appetite. The experimental treatments differed by supplementing the TMR with either 0 or $25 \mathrm{~g}$ of the EO-containing product per day and animal. This level was derived from the producer's recommendation of providing up to $22 \mathrm{~g}$ /day for cows weighing $600 \mathrm{~kg}$. The EO powder was top-dressed every morning on the daily TMR portion in each of 12 troughs accessible to groups of 12 cows (see below) and then mixed by hand with the TMR.

The TMR consisted, per kg dry matter (DM), of grass silage, $420 \mathrm{~g}$; maize silage, $357 \mathrm{~g}$; concentrate, $130 \mathrm{~g}$; hay, $45 \mathrm{~g}$; ensiled sugar beet pulp, $30 \mathrm{~g}$; ground maize, $18 \mathrm{~g}$. This TMR was calculated to have a milk production potential of $29 \mathrm{~kg}$ milk/day. Cows with a milk yield of $30 \mathrm{~kg} /$ day or more got access to additional energy- or protein-rich concentrate via automatic access-controlled concentrate feeding stations arranged in the pen.

In the experiment, 24 lactating primiparous and multiparous dairy cows, housed in a free-stall barn at the AgroVet-Strickhof research station (Lindau, Switzerland), were allocated in a randomised manner to two dietary treatment sequences. These comprised 12 cows each in an $\mathrm{AB} / \mathrm{BA}$ crossover design resulting in 24 observations per diet. Brown Swiss and Holstein (two times six in one treatment sequence group, and seven and five in the second treatment sequence group) were used. In addition, the two groups were balanced by milk yield, lactation number $(2.63 \pm 0.23)$, days in milk $(190 \pm 18.0)$ and SCC $\left(131 \pm 32.4 \times 10^{3} / \mathrm{ml}\right)$. At the start of the experiment, the cows yielded $35.7 \pm 0.9 \mathrm{~kg}$ of energy corrected milk (ECM). No cases of acute or chronic mastitis occurred in the present study.

\section{Data recording and sampling}

Each cow was subjected two times to a 2-week adaptation period followed by a 7-day period of daily data recording and sampling. The TMR amount consumed was recorded via transponders for each feeding event of each individual cow as weight change from before and to after the access to the trough. The amount of milk produced was recorded digitally (Metatron MB; GEA Farm Technologies, Bönen, Germany) in a tandem-type milking parlour equipped with automatic cow identification. Samples from the silages were collected once throughout the silo front, from top left to bottom right and thoroughly mixed. Hay samples were taken once from a hay bale and mixed thoroughly. A sample of each of the concentrates and the EO mix was taken directly out of their original containers. In addition, both TMR were sampled once from the troughs. All samples except that of the EO mix were dried for 4 days at the temperature of $60{ }^{\circ} \mathrm{C}$ and ground through a 1-mm-sieve. Individual representative milk samples were collected during the morning (05:00) and evening milking (15:45) on 3 days each of both 7-day sampling periods. The Metatron MB device of the parlour was also used to collect milk samples. Part of the milk samples was then frozen at a temperature of $-20{ }^{\circ} \mathrm{C}$ until analysis, another part was preserved with Bronopol (Suisselab AG, Zollikofen, Switzerland) for later analysis of milk composition. Body weight could not be determined during the experiment due to a malfunction of the cattle scale.

\section{Laboratory analyses}

Feed items were analysed for DM and total ash using the Thermogravimetric Analyzer TGA701 (Leco Corporation, St. Joseph, MI, USA; AOAC index no. 942.05; AOAC, 1995). For nitrogen analysis, the TruMac CN device (Leco Corporation, St. Joseph, MI, USA; AOAC index no. 968.06; AOAC, 1995) was used. Neutral detergent fibre (NDF) and acid detergent fibre (ADF) were analysed with the Fibretherm FT 12 System (Art. 13-0026; Gerhardt $\mathrm{GmbH} \&$ Co. KG, Koenigswinter, Germany). Heat stable $\alpha$-amylase (Termamyl; Novozymes, Bagsværd, Denmark) was used and NDF values were corrected for ash. Ether extract was analysed with the help of the extraction System B-811 (Büchi, Flawil, Switzerland; AOAC index no. 963.15; AOAC, 1995). Total extractable phenols (TEP), hydrolysable tannins (HT), condensed tannins (CT) and non-tannin phenols (NTP) in feed were assessed using the FolinCiocalteu method as described by Leparmarai et al. (2019).

In the Bronopol conserved milk, contents of fat, protein, lactose and urea were determined separately for each milking with a MilkoScan FT device (Foss, Hilllerod, Denmark) using mid-infrared spectroscopy. The SCC was assessed by flow cytometry with the Fossomatic FC (Foss, Hillerod, Denmark).

Milk coagulation properties were analysed with the Lattodinamografo (Foss, Padova, Italy). Properties measured included rennet coagulation time (RCT), curd firmness at $30 \mathrm{~min}$ after rennet addition $\left(\mathrm{A}_{30}\right)$ and after twice the RCT $\left(\mathrm{A}_{2 \mathrm{R}}\right)$, as well as rate of firming $\left(\mathrm{k}_{20}\right)$. For this analysis, $10 \mathrm{ml}$ samples of a mixture of cooled $\left(4{ }^{\circ} \mathrm{C}\right)$ evening and subsequent morning milk, collected on the last 2 days of the second sampling period and pooled according to milk 
yield, were used. These samples were mixed with $100 \mu \mathrm{l}$ of rennet (Pacovis Premium, $215 \mathrm{IMCU} / \mathrm{kg}$, 85\% chymosin; Pacovis Amrein AG, Belp, Switzerland) diluted to $4 \% \mathrm{v} / \mathrm{v}$ in distilled water and incubated at $36^{\circ} \mathrm{C}$ during $30 \mathrm{~min}$. Samples were analysed in triplicate.

The total phenols (TP) in milk were analysed based on the Folin-Ciocalteau method as described by Leparmarai et al. (2019). For the determination of the antioxidant capacity, $50 \mathrm{ml}$ of milk were defrosted at $4{ }^{\circ} \mathrm{C}$ overnight and diluted in acetone $(80 \%)$ to a mixture containing $35 \%$ milk. After vortexing, the solutions were incubated for $30 \mathrm{~min}$ on a shaker and centrifuged for $5 \mathrm{~min}$ at $10000 \mathrm{~g}$ and for another $5 \mathrm{~min}$ at $14500 \mathrm{~g}$. After this extraction step, the total antioxidant capacity (TAC) of the milk extract was determined with a commercial kit $\left(\right.$ OxiSelect $^{\mathrm{TM}}$ Total Antioxidant Capacity Assay Kit; Cell Biolabs, San Diego, CA, USA) following the manufacturer's instructions for aqueous food samples.

\section{Calculations and statistical analysis}

The data were analysed with SPSS (IBM SPSS Statistics ver. 24; IBM Corp., Armonk, NY, USA). Normal distribution of the data and the residuals was confirmed by visual inspection of the Q-Q-plots and the Shapiro-Wilk test. The ECM yield ( $\mathrm{kg} / \mathrm{day})$ was calculated as $0.327 \times$ milk yield $(\mathrm{kg} /$ day $)+12.95 \times$ fat yield $+7.2 \times$ protein yield, with fat and protein yield calculated as the respective percentage $\times$ milk yield / 100. To match normal distribution, SCC was converted into somatic cell score for statistical analysis by the formula $\log _{2}(\mathrm{SCC} / 100000)+3$. Considering the cross-over design, a repeated measures ANCOVA was applied, with diet as within-subject factor and the order of the treatment as between-subjects factor. For feed intake, feed efficiency, milk yield and milk composition (except lactose concentration), the preexperimental values were included as covariate. Milk coagulation properties, TP and TAC were determined only in milk samples from the second experimental period resulting in 12 observations per dietary treatment. These data were subjected to a linear mixed model analysis with feed, breed and their interaction as fixed effects and individual animals as random effect. $P<0.05$ was considered as statistically significant.

\section{Results and discussion}

\section{Feeds, supplement and diet composition}

The chemical composition of the feed items, the supplement and the two complete TMR types is described in Table 1. The commercial product containing the EO mixture was rich in non-fibre carbohydrates, NDF and ADF and low in crude protein and ether extract. The TEP were represented almost completely by the fraction of the NTP. This indicates that the EO extracted from eucalyptus, thyme and anise contained mostly phenols with low molecular weight, an observation described for thyme before (Aguilar and Hernández-Brenes, 2015). The other feed items, especially the grass silage, also contributed to the TEP, but here also the HT made a substantial contribution. Adding the supplement to the TMR increased the analysed TEP only by $0.4 \mathrm{~g} / \mathrm{kg}$ TMR DM.

Table 1. Chemical composition of the dietary ingredients, the mixture of essential oils (EO) and the total mixed rations (TMR) as analysed or estimated, $\mathrm{g} / \mathrm{kg}$ dry matter (DM)

\begin{tabular}{lcccccccc}
\hline Ingredient & Hay & $\begin{array}{c}\text { Grass } \\
\text { silage }\end{array}$ & $\begin{array}{c}\text { Maize } \\
\text { silage }\end{array}$ & Concentrate $^{1}$ & $\begin{array}{l}\text { Sugar beet } \\
\text { pulp silage }^{2}\end{array}$ & EO mix & TMR & TMR + EO mix \\
\hline DM, g/kg wet weight & 881 & 418 & 407 & 904 & 230 & 906 & 398 & 427 \\
Organic matter & 829 & 823 & 818 & 820 & 929 & 817 & 908 & 833 \\
Crude protein & 88.2 & 155 & 74.2 & 343 & 91.6 & 41.7 & 138 & 140 \\
Ether extract & 14.7 & 31.5 & 37.6 & 24.9 & 10.0 & 41.1 & 31.9 & 32.1 \\
Non-fibre carbohydrates $^{3}$ & 225 & 241 & 434 & 400 & 374 & 626 & 333 & 238 \\
Neutral detergent fibre (NDF) & 589 & 483 & 363 & 141 & 453 & 193 & 448 & 498 \\
Acid detergent fibre & 399 & 358 & 209 & 96.3 & 238 & 95.8 & 328 & 369 \\
Phenols & & & & & & & & 13.2 \\
$\quad$ total extractable phenols (TEP) & 9.6 & 17.9 & 10.1 & 5.1 & - & 20.9 & 12.8 & 13.2 \\
$\quad$ non-tannin phenols (NTP) & 7.7 & 14.0 & 8.5 & 4.6 & - & 20.8 & 10.6 & 10.3 \\
$\quad$ total tannins & 1.9 & 3.9 & 1.6 & 0.5 & - & 0.1 & 2.2 & 2.9 \\
$\quad$ condensed tannins (CT) & 0.3 & 0.5 & 0.1 & 0 & - & 0 & 0.3 & 0.3 \\
$\quad$ hydrolysable tannins (HT) & 1.7 & 3.4 & 1.5 & 0.4 & - & 0.1 & 1.9 & 2.6 \\
\hline
\end{tabular}

1 ingredients: soybean meal, triticale, rapeseed cake, dextrose, maize gluten meal, sodium bicarbonate, sodium chloride, calcium carbonate, mineral-vitamin premix; ${ }^{2}$ data obtained from www.feedbase.ch (accessed on 28 August 2019); ${ }^{3}$ calculated as: organic matter - (crude protein + ether extract + neutral detergent fibre); ' -' - no values provided 


\section{Effects of the EO mixture on intake, milk yield and milk gross composition}

The total dry matter intake(DMI) was significantly higher by $4 \%$ in the EO-supplemented group $(5 \mathrm{~g} \mathrm{EO} /$ day per cow) compared to the non-supplemented group (Table 2). This indicates a slight increase in palatability of the TMR caused by the addition of EO as suggested by the producer. Contrarily, a decline in DMI of dairy cows was reported by Hristov et al. (2013) when feeding EO from oregano (Origanum vulgare) in amounts of up to $0.75 \mathrm{~g} /$ day. by improving their health condition and thus their appetite.

Adding the EO mixture to the TMR did not significantly enhance milk yield and feed conversion efficiency in the present experiment (Table 2). This is in accordance with studies feeding lower or higher dosages of EO to dairy cows (Spanghero et al., 2009; Santos et al., 2010). However, Wall et al. (2014) found an increased milk yield when supplementing an encapsulated blend, but this was obviously only the consequence of the enhanced DMI, and feed

Table 2. Effect of the essential oil mixture (EO mix) on feed intake, milk yield and milk composition, $n=24$ per treatment

\begin{tabular}{|c|c|c|c|c|c|c|}
\hline \multirow[b]{2}{*}{ Indices } & \multicolumn{2}{|l|}{$\mathrm{TMR}^{1}$} & \multirow[b]{2}{*}{$\mathrm{SEM}^{2}$} & \multicolumn{3}{|c|}{$P$-value } \\
\hline & without EO & with EO & & diet & $\begin{array}{l}\text { order } \\
\text { of treatment }\end{array}$ & $\begin{array}{l}\text { diet } \times \text { order } \\
\text { of treatment }\end{array}$ \\
\hline \multicolumn{7}{|l|}{ Feed intake } \\
\hline dry matter intake $(\mathrm{DMl})^{3}, \mathrm{~kg} /$ day & 18.7 & 19.5 & 0.391 & 0.048 & 0.391 & 0.004 \\
\hline \multicolumn{7}{|l|}{ Milk yield, kg/day } \\
\hline absolute ${ }^{3}$ & 28.2 & 28.9 & 1.02 & 0.324 & 0.405 & 0.044 \\
\hline energy corrected $(\mathrm{ECM})^{3}$ & 32.0 & 32.8 & 1.12 & 0.331 & 0.988 & 0.556 \\
\hline Feed conversion efficiency ${ }^{3}, \mathrm{~kg}$ ECM $/ \mathrm{kg}$ DMI & | 1.64 & 1.67 & 0.090 & 0.882 & 0.469 & 0.067 \\
\hline \multicolumn{7}{|l|}{ Milk constituents } \\
\hline fat $^{3}, \%$ & 4.23 & 4.26 & 0.122 & 0.823 & 0.073 & 0.937 \\
\hline protein $^{3}, \%$ & 3.58 & 3.69 & 0.094 & 0.181 & 0.028 & 0.773 \\
\hline fat:protein ratio ${ }^{3}$ & 1.19 & 1.15 & 0.023 & 0.200 & 0.486 & 0.931 \\
\hline lactose, $\%$ & 4.70 & 4.63 & 0.048 & 0.181 & 0.748 & 0.332 \\
\hline urea $^{3}, \mathrm{mg} / 100 \mathrm{ml}$ & 28.3 & 25.5 & 0.96 & 0.780 & 0.822 & 0.972 \\
\hline somatic cell count ${ }^{3,4}, \times 10^{3} / \mathrm{ml}$ & 95 & 146 & 28.9 & 0.021 & 0.605 & 0.004 \\
\hline
\end{tabular}

The addition of $1.2 \mathrm{~g} /$ day of a mixture of thymol, eugenol, vanillin and limonene EO to the diet of early lactating dairy cows also decreased DMI compared to control cows (Tassoul and Shaver, 2009). Notably, in these two studies DMI was reduced even though the level of EO supplementation was much lower than in the present study. The hypothesis that the intense aroma of EO, and not a potential effect of EO on rumen processes, is the main reason for a potential decrease in DMI is supported by the lack of DMI suppression when Benchaar et al. (2007) supplemented dairy cows with $0.75 \mathrm{~g}$ /day of an EO mixture through a rumen fistula instead of orally. Similarly, encapsulating a blend of cinnamaldehyde and eugenol prevented adverse EO effects on palatability and thus increased DMI in the study of Wall et al. (2014). The product used in the present study is assumed by the producer to increase feed intake in cows with respiratory diseases, but the cows in our study did not suffer from such problems. Therefore, it still has to be demonstrated if the EO mixture might be able to indirectly lead to an increased DMI in cows with respiratory diseases conversion efficiency was not improved. By feeding dairy ewes a forage-based diet including $1.45 \mathrm{~kg}$ of a concentrate with either 50,100 or $150 \mathrm{mg}$ $\mathrm{EO} / \mathrm{kg}$ DM added via a product rich in thymol, eugenol, vanillin, guaiacol and limonene, Giannenas et al. (2011) found a dose-dependent increase in milk yield of up to $0.55 \mathrm{~kg} /$ day with the highest EO supplementation and, concomitantly, in feed conversion efficiency. An increased feed conversion efficiency was also observed when dairy cows were supplemented with oregano (Origanum vulgare L.) leaf material, but this at a decreased DMI (Hristov et al., 2013).

The EO mix did not affect the contents of protein, fat, lactose and urea in the milk in the present study (Table 2). The results described in the literature on the effects of EO on milk composition are very contradictory. Studies have reported increased contents of protein (Spanghero et al., 2009; Wall et al., 2014), fat (Santos et al., 2010) and lactose (Benchaar et al., 2007), and decreased urea contents (Giannenas et al., 2011; Hristov et al., 2013) in milk when supplementing dairy cows and ewes with EO. In these studies, 
always only one of the milk constituents was affected. The milk SCC was significantly increased by EO supplementation, but without reaching values indicative of mastitis. In contrast, Silva Filho et al. (2017) found a tendency to lower SCC when feeding $8 \mathrm{~g}$ thyme $\mathrm{EO} /$ day per cow which was a higher dose of thyme EO as that used in the present study. Also the highest dose of EO $(0.15 \mathrm{~g} / \mathrm{kg} \mathrm{DM})$ used in the study by Giannenas et al. (2011) significantly decreased SCC in sheep milk. This probably excludes simple dosage effects. The variable results might instead be explained in part by the vast number of different compounds in the various EO. Sometimes the bioactivity of an EO can be attributed to one or two of its major compounds, but in other cases the sum of several less abundant compounds seems to be more effective than any single major compound (Bakkali et al., 2008). The major component of the essential oil in eucalyptus is 1,8-cineole followed by $\alpha$-pinene (Sebei et al., 2015). Thyme EO can exhibit one of 20 different chemotypes, e.g. characterised by high contents of thymol or carvacrol (Satyal et al., 2016). The major component in the anise EO is trans-anethole (Orav et al., 2008). In an in vitro experiment by Kissels et al. (2017), trans-anethole and 1,8-cineole did not show any antibacterial effects whereas a synergistic effect was observed for carvacrol and thymol. Due to the synergistic and additive effects of EO compounds, the overall composition of different EO and a combination thereof may cause complex effects on rumen fermentation and animal metabolism, which makes it difficult to compare the results of studies using mixtures of different EO. Specifically, we do not have a plausible explanation for the apparent SCC promoting effect of the present EO mix.

\section{Effects of the EO mixture on milk coagulation properties}

The milk coagulation properties did not show any significant response to EO supplementation in the present study (Table 3). In an experiment with goats, feeding thyme leaves increased milk coagulation time while distilled thyme leaves decreased it (Boutoial et al., 2013). These different results are most likely due to the large difference in the supplemented amounts as the goats received thyme EO in amounts ranging from 0.04 to $0.12 \%$ of their total daily intake (thyme leaves contain between 1 and 1.6\% EO; Satyal et al., 2016) whereas the cows in the present study received only about $0.015 \%$ of EO per kg TMR DM. A high SCC, as is characteristic for mastitis, is associated with
Table 3. Effect of the essential oil mixture (EO mix) on milk coagulation properties, $n=12$ per treatment

\begin{tabular}{|c|c|c|c|c|c|}
\hline \multirow[b]{2}{*}{ Indices } & \multicolumn{2}{|l|}{$\mathrm{TMR}^{1}$} & \multicolumn{3}{|c|}{$P$-value } \\
\hline & $\begin{array}{l}\text { withou } \\
\text { EO }\end{array}$ & $\begin{array}{l}\text { with } \\
\text { EO }\end{array}$ & SEM $^{2}$ & diet breed & $\begin{array}{l}\operatorname{diet} x \\
\text { breed }\end{array}$ \\
\hline $\begin{array}{l}\text { Rennet coagulation time } \\
\text { (RCT), min }\end{array}$ & 16.7 & 17.2 & 1.18 & 0.8060 .546 & 0.932 \\
\hline Curd firming rate $\left(\mathrm{k}_{20}\right)$, min & 4.39 & 4.42 & 0.634 & 0.9820 .727 & 0.852 \\
\hline $\begin{array}{l}\text { Curd firmness at } 30 \mathrm{~min} \\
\left(\mathrm{~A}_{30}\right), \mathrm{mm}\end{array}$ & 31.8 & 31.6 & 2.75 & 0.9810 .763 & 0.502 \\
\hline $\begin{array}{l}\text { Curd firmness after } \\
2 \times \operatorname{RCT}\left(A_{2 R}\right)^{3}, m m\end{array}$ & 34.8 & 36.3 & 3.12 & 0.8290 .903 & 0.952 \\
\hline
\end{tabular}

${ }^{1}$ TMR - total mixed ration; ${ }^{2}$ SEM - standard error of the mean; ${ }^{3}$ for this parameter $n=6$

a poor cheese yield (Auldist et al., 1996) manifested by a longer RCT and less favourable curd firming (lower $\mathrm{k}_{20}$ and $\mathrm{A}_{30}$ ) than that found in normal milk (Le Maréchal et al., 2011). As EO might prevent or reduce the incidence of mastitis, the cheesemaking properties might subsequently be improved in the affected cows. However, the present product enhanced SCC instead of lowering it.

\section{Effects of the EO mixture on milk total phenols and antioxidant property}

The TP content of the milk was not significantly influenced by feeding the EO mixture compared to the control group (Table 4). Obviously, the dietary administration of phenols via the supplement was too small to make a pronounced difference. On the contrary, feeding distilled rosemary leaves significantly increased the polyphenol content in goat milk and in plasma of suckling goat kids (Jordán et al., 2010). Also in sheep, a certain, but very low efficiency of the transfer of phenols from feed to milk has been observed (Leparmarai et al., 2019). It is likely that the proportion of phenols that is absorbed largely differs among phenolic compounds, but specific studies about transfer rates of phenolic EO from feed to milk are missing.

Table 4. Effect of the essential oil mixture (EO mix) on total phenol content and total antioxidant capacity of the milk, $n=12$ per treatment

\begin{tabular}{|c|c|c|c|c|c|}
\hline \multirow[b]{2}{*}{ Indices } & \multicolumn{2}{|l|}{ TMR $^{1}$} & \multirow[b]{2}{*}{$\mathrm{SEM}^{2}$} & \multicolumn{2}{|l|}{$P$-value } \\
\hline & $\begin{array}{l}\text { without } \\
\text { EO }\end{array}$ & $\begin{array}{l}\text { with } \\
\text { EO }\end{array}$ & & diet breed & diet $\times$ breed \\
\hline $\begin{array}{l}\text { Total phenol } \\
\text { content, mg/l }\end{array}$ & 24.5 & 25.4 & 1.19 & 0.5540 .107 & 0.798 \\
\hline $\begin{array}{l}\text { Total antioxidant } \\
\text { capacity }^{3}, \mu \mathrm{M}\end{array}$ & 95.0 & 101.0 & 8.65 & 0.5930 .273 & 0.304 \\
\hline
\end{tabular}

${ }^{1}$ TMR - total mixed ration; ${ }^{2}$ SEM - standard error of the mean; ${ }^{3}$ uric acid equivalents 
The EO extracted from thyme, eucalyptus and anise, all included in the EO mixture tested in the present study, are known to have potent antioxidant properties (Mimica-Dukić et al., 2016). An improved plasma antioxidant capacity due to dietary intake of the EO mixture containing at least $13.5 \%$ thymol and $4.5 \%$ cinnamaldehyde was observed in weaned piglets (Zeng et al., 2015). Very few studies investigated the effect of phenols in the diet on the antioxidant properties of the milk (reviewed in Leparmarai et al., 2019). Aguiar et al. (2014) observed a significant increase in the antioxidant capacity of cow's milk when adding phenolic EO extracted from propolis obtained from an experimental farm in an eucalyptus plant reserve. It can, therefore, be assumed that the EO in this type of propolis were derived from eucalyptus plants and EO from eucalyptus were also present in the mixture investigated in the present study. However, we did not observe any effect of the supplementation with the EO mix on the milk antioxidant capacity of the experimental cows (Table 4). This suggests that either the dosage used or the proportion absorbed or both were not high enough to promote the antioxidant capacity of the milk in the present study.

\section{Conclusions}

The present study showed that adding a commercial product containing the mixture of essential oils (EO) from thyme, eucalyptus and anise in the amount recommended by the producer does not have any significant adverse effect on performance and various milk compositional and technological properties. Our findings therefore confirm that the examined EO mixture can be applied for the purpose of respiratory disease prevention, which it was designed for, without such restrictions. However, the amount of supplied EO was most likely too low to exhibit favourable effects on performance and milk quality known from the literature. The differences in the outcomes of the present compared to former studies might also be explained by the specific composition of the EO administered. A large variety of EO in different EO-containing plants can differ even within the same species due to geographical location. This represents an important challenge and an element of uncertainty difficult to control when performing research with natural EO extracts. To better understand the effects of single EO compounds and their combinations on the metabolism and production parameters of dairy cows, studies should be carried out to determine which compounds in isolated form and which defined mixtures of these compounds are most promising.

\section{Acknowledgements}

We would like to thank the staff of AgroVetStrickhof (Switzerland) for their support with the feeding experiment and the lab staff of the animal nutrition group for helping with the analyses.

\section{References}

Aguiar S.C., Cottica S.M., Boeing J.S., Samensari R.B., Santos G.T., Visentainer J.V., Zeoula L.M., 2014. Effect of feeding phenolic compounds from propolis extracts to dairy cows on milk production, milk fatty acid composition, and the antioxidant capacity of milk. Anim. Feed Sci. Technol. 193, 148-154, https://doi.org/10.1016/j.anifeedsci.2014.04.006

Aguilar O., Hernández-Brenes C., 2015. Use of modified phenolic thyme extracts (Thymus vulgaris) with reduced polyphenol oxidase substrates as anthocyanin color and stability enhancing agents. Molecules 20, 22422-22434, https://doi.org/10.3390/ molecules201219854

AOAC, 1995. Official Methods of Analysis. Association of Official Analytical Chemists, Arlington, VA (USA)

Auldist M.J., Coats S., Sutherland B.J., Mayes J.J., McDowell G.H., Rogers G.L., 1996. Effects of somatic cell count and stage of lactation on raw milk composition and the yield and quality of Cheddar cheese. J. Dairy Res. 63, 269-280, https://doi. org/10.1017/S0022029900031769

Bakkali F., Averbeck S., Averbeck D., Idaomar M., 2008. Biological effects of essential oils - a review. Food Chem. Toxicol. 46, 446-475, https://doi.org/10.1016/j.fct.2007.09.106

Benchaar C., Petit H.V., Berthiaume R., Ouellet D.R., Chiquette J., Chouinard P.Y., 2007. Effects of essential oils on digestion, ruminal fermentation, rumen microbial populations, milk production, and milk composition in dairy cows fed alfalfa silage or corn silage. J. Dairy Sci. 90, 886-897, https://doi. org/10.3168/jds.S0022-0302(07)71572-2

Boutoial K., García V., Rovira S., Ferrandini E., Abdelkhalek O., López M.B., 2013. Effect of feeding goats with distilled and nondistilled thyme leaves (Thymus zygis subsp. gracilis) on milk and cheese properties. J. Dairy Res. 80, 448-456, https://doi. org/10.1017/S0022029913000459

Burt S., 2004. Essential oils: their antibacterial properties and potential applications in foods - a review. Int. J. Food Microbiol. 94, 223-253, https://doi.org/10.1016/j.jfoodmicro.2004.03.022

Giannenas I., Skoufos J., Giannakopoulos C., Wiemann M., Gortzi O., Lalas S., Kyriazakis I., 2011. Effects of essential oils on milk production, milk composition, and rumen microbiota in Chios dairy ewes. J. Dairy Sci. 94, 5569-5577, https://doi. org/10.3168/jds.2010-4096

Hristov A.N., Lee C., Cassidy T., Heyler K., Tekippe J.A., Varga G.A., Corl B., Brandt R.C., 2013. Effect of Origanum vulgare L. leaves on rumen fermentation, production, and milk fatty acid composition in lactating dairy cows. J. Dairy Sci. 96, 1189-1202, https://doi.org/10.3168/jds.2012-5975

Jordán M.J., Moñino M.I., Martínez C., Lafuente A., Sotomayor J.A., 2010. Introduction of distillate rosemary leaves into the diet of the Murciano-Granadina goat: transfer of polyphenolic compounds to goats' milk and the plasma of suckling goat kids. J. Agric. Food Chem. 58, 8265-8270, https://doi.org/10.1021/jf100921z

Kissels W., Wu X., Santos R.R., 2017. Interaction of the isomers carvacrol and thymol with the antibiotics doxycycline and tilmicosin: In vitro effects against pathogenic bacteria commonly found in the respiratory tract of calves. J. Dairy Sci. 100, 970-974, https:// doi.org/10.3168/jds.2016-11536 
Lambert R.J.W., Skandamis P.N., Coote P.J., Nychas G.-J.E., 2001. A study of the minimum inhibitory concentration and mode of action of oregano essential oil, thymol and carvacrol. J. Appl. Microbiol. 91, 453-462, https://doi.org/10.1046/j.13652672.2001.01428.x

Le Maréchal C., Thiéry R., Vautor E., Le Loir Y., 2011. Mastitis impact on technological properties of milk and quality of milk products - a review. Dairy Sci. Technol. 91, 247-282, https://doi. org/10.1007/s13594-011-0009-6

Leparmarai P.T., Sinz S., Kunz C., Liesegang A., Ortmann S., Kreuzer M., Marquardt S., 2019. Transfer of total phenols from a grapeseed-supplemented diet to dairy sheep and goat milk, and effects on performance and milk quality. J. Anim. Sci. 97, 1840-1851, https://doi.org/10.1093/jas/skz046

Mimica-Dukić N., Orčić D., Lesjak M., Šibul F., 2016. Essential oils as powerful antioxidants: Misconception or scientific fact? In: V.D. Jeliazkov, C.L. Cantrell (Editors). ACS Symposium Series Vol. 1218. Medicinal and Aromatic Crops: Production, Phytochemistry, and Utilization. American Chemical Society. Washington, DC (USA), pp. 187-208, https://doi.org/10.1021/ bk-2016-1218.ch012

Moghaddam M., Mehdizadeh L., 2017. Chapter 13 - Chemistry of essential oils and factors influencing their constituents. In: A.M. Grumezescu, A.M. Holban (Editors). Handbook of Food Bioengineering Vol. 3. Soft Chemistry and Food Fermentation. Academic Press, New York, NY (USA), pp. 379-419, https:/l doi.org/10.1016/B978-0-12-811412-4.00013-8

Orav A., Raal A., Arak E., 2008. Essential oil composition of Pimpinella anisum L. fruits from various European countries. Nat. Prod. Res. 22, 227-232, https://doi.org/10.1080/14786410701424667

Santos M.B., Robinson P.H., Williams P., Losa R., 2010. Effects of addition of an essential oil complex to the diet of lactating dairy cows on whole tract digestion of nutrients and productive performance. Anim. Feed Sci. Technol. 157, 64-71, https://doi. org/10.1016/j.anifeedsci.2010.02.001

Satyal P., Murray B.L., McFeeters R.L., Setzer W.N., 2016. Essential oil characterization of Thymus vulgaris from various geographical locations. Foods 5, 70, https://doi.org/10.3390/foods5040070

Sebei K., Sakouhi F., Herchi W., Khouja M.L., Boukhchina S., 2015. Chemical composition and antibacterial activities of seven Eucalyptus species essential oils leaves. Biol. Res. 48, 7, https://doi.org/10.1186/0717-6287-48-7
Silva Filho E.C., Roma Junior L.C., Salles M.S.V., Salles F.A., Ezequiel J.M.B., Van Cleef E.H.C.B., 2017. Thyme essential oil supplementation on performance and milk quality of lactating dairy cows. In: Book of Abstracts of the $68^{\text {th }}$ Annual Meeting of the European Federation of Animal Science. Tallin (Estonia). Wageningen Academic Publishers, Wageningen (The Netherlands), p. 204, http://www.eaap.org/Annual_ Meeting/2017_tallin/eaap_boa_68th_2017.pdf

Soycan-Önenç S., Koc F., Coşkuntuna L., Levent Özdüven M., Gümüș T., 2015. The effect of oregano and cinnamon essential oils on fermentation quality and aerobic stability of field pea silages. Asian-Australas. J. Anim. Sci. 28, 1281-1287, https:// doi.org/10.5713/ajas.15.0122

Spanghero M., Robinson P.H., Zanfi C., Fabbro E., 2009. Effect of increasing doses of a microencapsulated blend of essential oils on performance of lactating primiparous dairy cows. Anim. Feed Sci. Technol. 153, 153-157, https://doi.org/10.1016/j. anifeedsci.2009.06.004

Tassoul M.D., Shaver R.D., 2009. Effect of a mixture of supplemental dietary plant essential oils on performance of periparturient and early lactation dairy cows. J. Dairy Sci. 92, 1734-1740, https:// doi.org/10.3168/jds.2008-1760

Tisserand R., Young R., 2013. Essential Oil Safety. $2^{\text {nd }}$ Edition. Churchill Livingstone (Elsevier). London (UK)

Tornambé G., Cornu A., Pradel P., Kondjoyan N., Carnat A.P., Petit M., Martin B., 2006. Changes in terpene content in milk from pasture-fed cows. J. Dairy Sci. 89, 2309-2319, https://doi. org/10.3168/jds.S0022-0302(06)72302-5

Wall E.H., Doane P.H., Donkin S.S., Bravo D., 2014. The effects of supplementation with a blend of cinnamaldehyde and eugenol on feed intake and milk production of dairy cows. J. Dairy Sci. 97, 5709-5717, https://doi.org/10.3168/jds.2014-7896

Zeng Z., Xu X., Zhang Q., Li P., Zhao P., Li Q., Liu J., Piao X., 2015. Effects of essential oil supplementation of a low-energy diet on performance, intestinal morphology and microflora, immune properties and antioxidant activities in weaned pigs. Anim. Sci. J. 86, 279-285, https://doi.org/10.1111/asj.12277 